\title{
Measuring Vote-Selling: Field Evidence from the Philippines
}

\author{
By Allen Hicken, StePhen Leider, Nico Ravanilla And Dean YanG*
}

\begin{abstract}
* Hicken: Department of Political Science, University of Michigan, Ann Arbor, MI, 48109 (ahicken@umich.edu). Leider: Stephen M. Ross School of Business, University of Michigan, Ann Arbor, MI, 48109 (leider@umich.edu). Ravanilla: Department of Political Science and Gerald R. Ford School of Public Policy, University of Michigan, Ann Arbor, MI, 48109 (rnico@umich.edu). Yang: Department of Economics and Gerald R. Ford School of Public Policy, University of Michigan, Ann Arbor, MI 48109 (deanyang@umich.edu). We thank Joma Gonzalez (Innovations for Poverty Action) for unparalleled field management, and Vibha Mehta for her contributions to the field work and analysis. This study was made possible by funding from the MCubed initiative at the University of Michigan.
\end{abstract}

Many developing democracies struggle with vote-buying and other forms of clientelism in electoral politics. Clientelism has been associated with reduced accountability and trust, increased corruption, and inefficient public administration (Stokes 2005; Desposato 2007, Keefer 2007, Kitscheldt et al. 2010, Hicken and Simmons 2008, Hicken 2011, Stokes et al. 2013). In response, many government agencies and non-governmental organizations have attempted to combat votebuying, primarily by convincing voters not to sell their votes. Anti-vote-selling campaigns generally urge voters either to not accept money from candidates in the first place, or to "vote your conscience" despite taking money
(Schaffer 2005). ${ }^{1} \quad$ However, there is little work on whether such campaigns are effective at reducing vote-selling.

We conducted a field experiment during the 2013 Philippine elections to test the effectiveness of interventions against voteselling. A central challenge in assessing the impact of any anti-vote-selling effort, including ours, is creating a valid measure of vote-selling. Measuring vote-selling is clearly not a trivial endeavor, particularly in contexts (including the Philippines) where individual votes are not publicly observed.

In this paper, we describe a proxy measure that we constructed out of self-reports of Philippine voters participating in our experiment, and present empirical patterns of correlation that we argue help validate it as a measure of vote-selling. This measure is the key outcome variable in the experiment, whose results are described in full in Hicken et al (2014).

We first describe the context, data collection, and the experimental treatments,

\footnotetext{
1 A prominent example was the Archbishop of Manila exhorting voters to "take the bait but not the hook" during Marcos-era presidential elections.
} 
before turning to the proxy measure of voteselling and its correlates.

\section{Context and Experimental Design ${ }^{2}$}

We conducted our study in Sorsogon City, Philippines during the May 2013 municipal elections. Vote-buying is widespread in this region, as in other areas of the country. Most of the vote-buying occurs in the last few days before the election. Representatives of a candidate offer likely voters money or goods in return for their vote. The Philippines uses secret electronic balloting, so vote-buyers cannot directly verify an individual's vote, but must instead rely on trust and reciprocity. ${ }^{3}$ The amount of money offered by candidates varied widely, both across races, and between candidates. Mayor and vice-mayor candidates typically offered between 250 and 500 pesos (US\$5.57-\$11.14), while city council candidates offered 20 to 100 pesos (US\$0.45\$2.23). Our data collection occurred in two waves: a baseline survey in the month leading up to the election, as well as a post-election survey.

\section{A. Baseline Survey}

During the baseline survey enumerators visited randomly selected households and

\footnotetext{
2 Additional details are available in Hicken et al. (2014).

3 Finan and Schecter (2012) demonstrate that politicians disproportionately target reciprocal voters for vote-buying.
}

conducted 883 surveys. Study participants were asked to rate each candidate for mayor, vice-mayor and city council on a 7-point scale (ranging from "extremely unfavorable" to "extremely favorable"). At the end of the survey, all participants were shown a threeminute voter education video produced by a Philippine actress and activist that urged voters not to sell their vote.

\section{B. The Experiment}

Participants were randomly assigned to one of three treatment conditions. In the control group, the baseline interaction ended after the video clip. Two treatment interventions (Promise 1 and Promise 2) invited participants to promise not to sell their vote. Participants randomly assigned to the Promise 1 treatment group were asked to promise not to accept money from any candidates, while participants assigned to the Promise 2 treatment were asked to promise to "vote your conscience," even if they took money from a candidate.

We consider outcomes in three types of municipal elections: mayor, vice-mayor and city council. We are interested in the impact of the promise treatments on vote-selling by study participants.

\section{Post-Election Survey}


In the month following the election, participants were surveyed a second time. Participants reported whether they had voted, and who they had voted for in each race. Voters could vote for one candidate for mayor, one candidate for vice-mayor, and up to four candidates for city council. ${ }^{4} \mathrm{We}$ experienced very little attrition between waves $-95.9 \%$ of baseline participants completed the post-election survey, with no significant difference in attrition between treatments.

\section{Proxy Measure of Vote-Selling}

We cannot directly observe vote-selling, and therefore must use a proxy measure. We construct a measure of "vote-switching" as a proxy for vote-selling. In the mayoral and vice-mayoral races, we say that a voter switched if they report voting for a candidate who was not their highest rated candidate (including ties) in the baseline survey. For the city-council race, we say that a voter switched if they voted for at least one candidate that was not in their top four highest rated candidates (including ties) in the baseline survey. We identify if a voter switched in any of the races. Overall, we observed $56 \%$ of

\footnotetext{
4 Sorsogon City is divided into three separate districts for the City Council election. Each district had between 11 and 13 candidates.
}

voters switching in at least one race, with $12 \%$ switching for mayor, $22 \%$ switching for vicemayor and $44 \%$ switching for city council.

There are many innocuous and legitimate reasons why a voter may have switched their vote. For example, they could have acquired more information about candidates, or decided to evaluate that information differently. However, vote-switching for these reasons should be equally likely in each treatment condition, and, due to randomization, should be orthogonal to the treatments. If a promise treatment leads to a change in vote-switching, it should reflect a change in actual voteselling.

A limitation of our data is that we must rely on self-reported voting. One concern is that a reduction in vote-switching may be driven by a social desirability bias in our survey responses, rather than a real change in voting behavior. In Hicken et al. (2014) we explicitly model how a social desirability bias would affect survey responses in this setting, and demonstrate that the pattern of our treatment results are not consistent with such a bias. In short, we would expect that the bias would lead to the largest reduction in reported switching in the more important mayoral and vice-mayoral elections, while the bias would be the smallest in the less important city council elections. By contrast, we find that 
our interventions reduce switching the most in the city council race.

\section{A. Relationship between Voter Preferences and Vote-Switching}

If the vote-switching measure accurately reflects real voting patterns, we would expect that vote-switching would be related with voters' candidate ratings. Specifically, we would expect that a voter would be most likely to switch if the difference in favorability ratings between the voter's initially preferred candidate and the highest-rated other candidate is small. Conversely, we would expect voters to be less likely to switch when the most attractive alternative candidate is rated much worse than the preferred candidate.

For each race we calculate a "favorability gap": the difference in favorability rating between the voter's preferred candidate and the highest rated non-preferred candidate. For the city council race we use the lowest rating among the voter's top 4 preferred candidates and subtract the highest rating among the voter's other non-preferred candidates. When pooling across races, we take the minimum favorability gap, since this is the race where we would expect the switch to occur.

Column 1 of Table 1 reports the results of regressing the indicator for switching in any race on the favorability gap for all races. ${ }^{5} \mathrm{We}$ find that switching probability is significantly decreasing in favorability gap, with a onecategory favorability gap (out of seven) leading to a 13 percentage point decrease in switching probability. We find similar results for each race separately. A one category difference is associated with a $7 \%$ reduction in switching in the mayoral race $(\beta=-0.070$, s.e. $=0.009)$, a $4 \%$ reduction for the vice-mayoral race $(\beta=-0.044$, s.e. $=0.013)$, and a $6 \%$ reduction in the city council race $(\beta=-0.064$, s.e. $=0.021)$. Hence, our vote-switching measure is related in an intuitive way to a voter's underlying candidate preferences.

\begin{tabular}{lcc}
\multicolumn{2}{c}{ TABLE $1-$ FAVORABILITY AND VOTE-BUYING GAPS } \\
\hline \multicolumn{3}{c}{ Switching in Any Race } \\
\hline Favorability Gap & $-0.133^{* * * *}$ \\
& $(0.0179)$ & \\
Vote-Buying Gap & & $0.232^{* * *}$ \\
& $\mathrm{Y}$ & $(0.0261)$ \\
Demographic Controls & $\mathrm{Y}$ \\
Constant & $0.785^{* * *}$ & $0.319^{* * *}$ \\
& $(0.131)$ & $(0.137)$ \\
Observations & 748 & 748 \\
\hline
\end{tabular}

Notes: OLS with robust standard errors. The dependent variable is an indicator that equals one if the voter voted for a non-favorite candidate in at least one race. Column 1: For each race we calculate the difference in favorability rating between the voter's preferred candidate (lowest rated among the top 4 for the city council race) and the highest rated non-preferred candidate. Favorability Gap is the minimum difference across races. Column 2: For each race we calculate the difference in vote-buying rating between the voter's preferred candidate (lowest rated among the top 4 for the city council race) and the highest vote-buying rating among non-preferred candidate. Vote-Buying Gap is the maximum difference across races. Demographic controls include age, gender, religion, number of household voters, employment, education, migrant status and marital status. *** Significant at the 1 percent level, $* *$ Significant at the 5 percent level, * Significant at the 10 percent level.

\footnotetext{
5 Regressions also include demographic controls. Regressions for individual races are reported in the Online Appendix. Full regression results are available from the authors upon request.
} 


\section{B. Relationship between Candidates' Vote-} Buying and Vote-Switching

We now examine how differences between candidates in the amount of money offered is related with vote-switching. We asked our survey enumerators to rate the vote-buying activities of each candidate on a 5-point scale (where $1=$ "not at all" and $5=$ "very much"). ${ }^{6}$ As expected, mayoral candidates had the highest rating for vote-buying (avg. = 4.97), followed by vice-mayor (3.49) and city council (2.75). For the city council race, there is also a large variation in the ratings between candidates (st. dev. $=0.78$ ).

For each voter, we can compare the average rating for "dropped" candidates (i.e. candidates rated in the top 4 , but not voted for) and "added" candidates (i.e. candidates not in the top 4, but voted for). Added candidates have a significantly higher rating than dropped candidates (3.21 vs. 2.76 ; signrank test $\mathrm{p}<0.01^{7}$ ) - indicating that voters are disproportionately switching towards candidates who are doing more vote-buying. This is what one would expect if switching

\footnotetext{
6 Our enumerators were able to directly observe a number of examples of candidate's cash offerings (see the appendix of Hicken et al. 2014 for examples), as well as learn of the amounts offered by candidates from friends and family.

7 The within-subject comparison is significant for each district individually, as well as for each treatment separately.
}

behavior is being predominately influenced by vote-buying.

For each voter, we can also calculate the "vote-buying gap" - the difference in the votebuying rating of the voter's preferred candidate $^{8}$ and the highest rating among all other candidates. The larger the money gap, the greater the imbalance between the amount of money being offered by the voter's preferred candidate and an alternative candidate. We would expect that switching would be more likely to occur when this difference is large. We also construct a measure of the vote-buying gap pooled across races, in which we take the maximum votebuying gap, since this is what should determine whether any switching should occur in any of the races.

In Column 2 of Table 1 we regress voteswitching on the vote-buying gap. We find that switching increases with money gap: a one-point larger money gap is associated with an increase in the likelihood of switching in any race of $23 \%$. The corresponding increase is $17 \%$ in the vice-mayor race ( $\beta=0.172$, s.e. $=0.034)$, and $24 \%$ in the city council race $(\beta=$ 0.238 , s.e. $=0.032)^{9}$

\footnotetext{
8 For the city council race we use the minimum rating among favorite candidates.

9 We cannot look at the mayor's race individually, since the two candidates had essentially the same rating.
} 


\section{Discussion}

In this paper we examine a proxy measure of vote-selling. We compare respondents' preelection ratings of candidates in three municipal electoral races with the candidates they reported actually voting for post-election. We construct an indicator of "vote-switching," capturing whether a respondent voted for a candidate who was not his or her initially most-preferred candidate (or in the set of most-preferred candidates, for an election where one votes for multiple candidates).

We show empirical patterns in "voteswitching" that validate its use as the key dependent variable of interest in our experimental study of the impact of anti-voteselling interventions (Hicken et al 2014). First, we show that voters who have weaker preference differences between candidates are more likely to vote-switch. Because this pattern is consistent with many reasons behind vote-switching, of which vote-selling is only one, this pattern simply indicates that voteswitching patterns are plausibly related with voter preference intensity.

Second, we show that voters are more likely to vote-switch when their initially-preferred candidate does less vote-buying compared to other competing candidates. Hence differences in vote-switching are much more likely to be driven by vote-selling than by other potential causes of vote-switching.

In Hicken et al (2014), we take "voteswitching" as our main dependent variable, and estimate the impact of two anti-voteselling treatments. There, we argue that the variation in "vote-switching" induced by the treatments should be interpreted as variation in vote-selling. That argument is bolstered by the patterns we find in this paper, in particular the relationships shown between voteswitching and vote-buying by candidates initially not preferred by respondents.

In that paper, we find that inviting voters to promise not to accept money does substantially reduce vote-switching, with the reduction we observe coming entirely from the city council election where candidate payments are smallest. Inviting promises to vote one's conscience do not reduce voteswitching overall. In fact, this treatment increases vote-selling in the mayoral and vicemayoral races, where larger amounts of money are being offered. We propose a behavioral model that can explain the differences in treatment effects between promises and across races. Key to the model is that accepting money from a candidate creates a temptation to actually vote for the votebuyer on election day, and that voters many not fully anticipate the magnitude of this 
temptation. A promise to "take the money but vote one's conscience" actually increases the number of voters accepting money, since they believe that the promise will allow them to accept the money without changing their votes. However, if the temptation is greater than anticipated, the promise will actually increase vote-switching. The model generates predicted differences in results between promises and between races that are verified in our data.

\section{REFERENCES}

Desposato, Scott W. 2007. "How does vote buying shape the legislative arena?" In Elections for Sale: The Causes and Consequences of Vote Buying. Schaffer F.C. ed. Boulder, CO: Lynne Rienner. pp. 144-179.

Finan, Frederico and Laura Schecter. 2012. "Vote-buying and Reciprocity." Econometrica: 80(2): 863-881.

Hicken, Allen. 2011. “Clientelism.” Annual Review of Political Science. 14(1): 289310.

Hicken, Allen, Stephen Leider, Nico Ravanilla and Dean Yang. 2014. "Temptation in Vote-Selling: Evidence from a Field Experiment in the Philippines." Working paper.

Hicken, Allen and J.W. Simmons. 2008.
"The personal vote and the efficacy of education spending." American Journal of Political Science. 52(1): 109-124.

Keefer, Philip. 2007. "Clientelism, credibility and the policy choices of young democracies." American Journal of Political Science. 51(4): 804-821.

Kitschelt, Herbert, Kirk A. Hawkins, Juan Pablo Luna, Guillermo Rosas and Elizabeth J. Zechmeister. 2010. Latin American Party Systems. Cambridge, UK: Cambridge University Press.

Schaffer, Frederic Charles. 2005. "Clean Elections and the Great Unwashed: Educating Voters in the Philippines." Occasional Paper 21, School of Social Science, Institute for Advanced Study.

Stokes, Susan C. 2005. "Perverse accountability: A formal model of machine politics with evidence from Argentina." American Political Science Review, 99(3): 315-325.

Stokes, Susan C., Thad Dunning, Marcelo Nazareno, and Valeria Brusco. 2013. Brokers, Voters and Clientelism: The Puzzle of Distributive Politics. Cambridge, UK: Cambridge University Press. 
